discovery of Earth's magnetosphere, not suspected beforehand.

For those scientists who have worked in NASA projects, or expect to, Dr Newell's concluding chapters will be of greatest interest. They deal with "the real world of budgets and finances"'. They seem at times to be a plea for more understanding by scientists of how competitive are the claims for NASA's favour.

Dr Newell is perhaps still too much the diplomat to render a critical historical treatment of the struggle between scientists and engineers within NASA and between unmanned and manned programmes. Such struggles persist to this day. The author, taking note of bitter feelings among scientists towards the manned programme, does remind them that even if they had succeeded in reducing or cancelling a project such as Apollo, there was little likelihood that much, if any, of the money saved would have been diverted to them. To the contrary, he observes, science generally benefited from Apollo by riding on its coattails for such lunar science endeavours as Surveyor and Lunar Orbiter. Moreover, he contends that scientists should have been grateful that they had a civilian agency like NASA rather than having to depend on military suppport, as had been the case in the pre-Sputnik days.

As for the future, Dr Newell proffers cautious optimism about the place of space science in NASA's operations, or at least he puts the best light on post-Apollo developments. Out of the "searching scrutiny" in the early 1970s, he writes, "emerged an acceptance of a continuing role for the agency in which science, applications, and exploration would all play a part'". Moreover, the author says, NASA's position became "intrinsically stronger" because it is now "freed at last from an uneasy dependence on a passing sense of urgency over the nation's technological strength relative that of the USSR'".

A failure of the book is the absence of any critical evaluation of the structure for the support of space science as it has evolved. Would space science be served better if it could count on several major sources of funds, not just NASA?

Dr Newell does advise that scientists must scale down some of their expectations if they are to win continuing support from NASA. These words are only now being heeded. Resistance by recent Administrations to large, new projects - the expensive planetary missions in particular - has prompted scientists working with NASA to shift their thinking to more modest goals.

Accordingly, the Space Science Exploration Committee, formed by NASA last year and chaired by Noel Hinners, Director of the National Air and Space Museum, is devising a new strategy. Missions with limited, specialized scientific objectives, employing lower-cost, standardized spacecraft, would be emphasized. Major undertakings, on the scale of another Viking or Space Telescope, would have little or no place in planning for the foreseeable future.

It remains to be seen how acceptable this modest strategy will be to NASA's managers or the Reagan Administration. A review of the American space programme, being prepared now by the White House Office of Science and Technology Policy, will presumably have more influence on the future course of NASA than any group of scientists. If the Administration's pronouncements are any indication, the review will deal almost exclusively with the space shuttle and policy regarding NASA's jurisdiction vis-à-vis the Department of Defense. Meanwhile, the engineers in NASA are drawing up plans for another big project, the manned space station, that would probably absorb any funds released as a result of the shuttle's completion.

This can only give scientists new reason to be uneasy. The entire American space programme is in a state of flux, with the ascendancy of the Pentagon in space affairs and the re-ordering of NASA's goals and responsibilities. It is in times like these that space scientists may find themselves wishing Homer Newell was still in a position to attend to their interests within the chambers of NASA.

John Noble Wilford is a science correspondent of The New York Times who covers NASA. His most recent book is The Mapmakers (Junction Books/Knopf, 1982).

\section{Heroes of AI}

\section{Richard Gregory}

Science Observed: Essays Out of My Mind. By Jeremy Bernstein. Pp.376. ISBN 0-465-07340-9. (Basic Books: 1982.) $\$ 16.95$.

THIS is a personal account, in 17 essays, of recent highlights of physics and of artificial intelligence. The pieces are written in lively style by Jeremy Bernstein, a professor of physics and author of several well-known books, including $A$ Comprehensible World (1961), The Analytical Engine (1964), Einstein (1973), Experiencing Science (1978) and Hans Bethe: Prophet of Energy (1980). He also writes on science for the New Yorker.

Like ancient sagas, these essays are based on heroes, on men of science confronting the unknown and sometimes each other. Chief among them are Marvin Minsky, Einstein, Robert Oppenheimer, Schrödinger and Harold Furth. Others lie in the shadows, seen with fleeting ambiguities: Ernst Mach - father and disowner of relativism. Charles Babbage grandfather of artificial intelligence, who set out to weave algebraic patterns with his analytical engine, just as the Jacquard loom weaves flowers and leaves. Babbage spoke most clearly through the voice of Ada Augusta, Countess of Lovelace, rejected daughter of the poet Byron. And Alan Turing - father of artificial intelligence, who dared to oppose the wit of men against machines, to see if under their disguises men and machine are the same. (Or is oil thicker than blood?)

The first principal hero is the guiding genius of artificial intelligence at MIT, Marvin Minsky. Indeed he is, as I know by acquaintance and not only description, all that Jeremy Bernstein claims. With his equally brilliant colleague John MacCarthy, now at Stanford, he started the AI enterprise in the United States in the late 1950s, and they invented its name. "Artificial intelligence" is philosophically better than the rival "Machine intelligence", for if brains are intelligent machines the colours may get confused.

Minsky is a compelling writer as well as a delightful companion and true inspirer of students. Disarmingly, he dislikes the activity of programming, preferring to think and discuss and write in words. Of intelligence, Minsky wrote in 1961 (quoted on p.54): "To me 'intelligence' seems to denote little more than the complex of performances which we happen to respect, but not understand". And, "Programmers, too, know that there is never any 'heart' in a program. There are high level routines in each program, but all they do is dictate that if such and such, then transfer to such and such a subroutine". And, "When we look at the low-level routines, which actually 'do the work', we find senseless loops and sequences of trivial operations, merely carrying out the dictates of their superiors".

There is much of interest here on the history of computing, with figures of the sizes and costs and weights and energy consumptions, as well as the speed and power of ancient and modern computers through their generations. It is indeed astonishing that ENIAC, which in the late 1940 s was the most complicated electronic device ever built, was a hundred feet long, ten feet high and three deep. It consumed 140 kilowatts, to handle twenty ten-digit "words" in its memory. On this scale, one could not get a present-day home computer into the house, or even the street.

Jeremy Bernstein is a scientist writing for scientists. He assumes that one knows about Mach's principle and Newton's bucket; and he also comments economically and without gush on such matters as the idiocy of using troops to test the effects of atom bomb blast and how well they would stand up psychologically to nuclear war. These are extremely readable sagas of our age; and they are well worth reading.

Richard Gregory is Professor of Neuropsychology and Director of the Brain and Perception Laboratory at the University of Bristol. 